\title{
Ranking Academic Performance Using Fuzzy Vikor: A Case of Secondary Schools At Perlis
}

\author{
Siti Nor Nadrah Muhamad*1, Rasyidah Abd Halim², Wan Nurshazelin Wan Shahidan², Nordianah \\ Jusoh $^{4}$, Saida Farhanah Sarkam ${ }^{5}$ \\ ${ }^{1,2,3}$ Faculty of Computer and Mathematical Sciences, Universiti Teknologi MARA Perlis Branch, \\ Malaysia \\ ${ }^{4}$ Faculty of Computer and Mathematical Sciences, Universiti Teknologi MARA Alor Gajah Branch, \\ Malaysia \\ ${ }^{5}$ Faculty of Business and Management, Universiti Teknologi MARA Alor Gajah Branch, Malaysia
}

Corresponding author: *nadrahmuhamad@perlis.uitm.edu.my

Received Date: 1 August 2018

Accepted Date: 12 November 2018

\begin{abstract}
Ranking is the process of structuring alternatives in order of priority. It is based on the criteria determined for each alternative involved. In this study, the researcher analyzed the percentage of candidates who scored in the 2016 Malaysia secondary school national examination, Sijil Pelajaran Malaysia (SPM), in the state of Perlis. The schools represent an alternative, while the examination subjects as the criterion. The study used fuzzy VIKOR method to determine the priority rank for the performance of five schools. Fuzzy VIKOR method evaluates the criteria and compose composite index of each alternative for the purpose of arranging them in order of preference alternatives. The result showed that fuzzy VIKOR method is able to rank the data more fair and accurate than other conventional methods such as TOPSIS (Technique for Order Preference by Similarity to an Ideal Solution) and PROMETHEE (Preference Ranking Organization METHod for Enrichment Evaluations). By using the proposed approach, the ambiguity involved in the evaluation data can be effectively represented and processed to assure a more effective evaluation process. The accurate ranking of schools might benefit the Education Ministry at the district level as more resources could be provided to the least performed school.
\end{abstract}

Keywords: Fuzzy, Fuzzy VIKOR Method, Defuzzification, School Ranking, Performance Evaluation, Multi criteria decision making (MDCM)

\section{INTRODUCTION}

In the last few years, the evaluation of the education system with excellent schools ranks has become an increasingly popular benchmark of the education system (Musani \& Jemain 2015). This is because using school ranking as a school performance evaluating tool will provide a good impression for school with higher rank. The good-ranked schools will not only bring pride to the teachers and administrators, but also encourages parents to send their children to the schools. Furthermore, the local authority might decide to allocate more resources to the low-performing schools so that they could be as good (Tierney 2013). On the other side of coin, the poor-ranked schools might motivate the school administrators to improvise their future performance, especially for students' achievement in national examination.

Besides that, it is important for school administration to increase the positive publics' perception to the school. In addition, it also affects the expenses allocated for student recruitment and operations, as well as acting as a guide for the school strategic planning. Hence, it will identify the school's needs of assistance 
in terms of infrastructure, financing, enhancement of teachers and also for the development of conducive teaching and learning environment.

Literature shows there are a lot of conventional methods in multi criteria decision making (MDCM) evaluation, however, less study applies fuzzy VIKOR method in order to rank schools performance, especially for daily schools in northern Malaysia. The fuzzy VIKOR method provides accurate information in evaluating school performance using the quantitative and qualitative data. This study uses data to measure the rank of school's academic achievement in Sijil Pelajaran Malaysia (SPM), the national examination for secondary school students in 2016. Based on the data, varieties of information for each school can be analyzed in a fair and accurate manner where the results can reflect the actual performance of the school.

\section{VIKOR METHOD}

VIKOR method is a multi-criteria optimization which can solve multi criteria decision making (MCDM) problem with conflicting and noncommensurable criteria. It assumes an acceptable compromise for conflict resolution as decision-makers want a solution that is closest to the ideal and the alternative is assessed according to the set of criteria. VIKOR method can obtain the gap between the ideal alternative and each alternative, the rank order of alternatives, and the priority of improving the weaknesses of each alternative (Kuo \& Liang 2012). Therefore, some studies extend the VIKOR method to solve the problems of uncertain conditions, as this method deals with clear-cut and uncertain data simultaneously.

Opricovic and Tzeng (2007) compares extended VIKOR method with three multi criteria decision making methods namely TOPSIS (Technique for Order Preference by Similarity to an Ideal Solution), PROMETHEE (Preference Ranking Organization Method for Enrichment Evaluations) and ELECTRE (Elimination and (Et) Choice Translating Reality) method to deal with hydropower systems, which the authors proved that Fuzzy VIKOR is the best solution in ranking alternatives.

\section{FUZZY VIKOR METHOD}

Fuzzy theory proposed that human thinking are linguistic variables of fuzzy sets rather than real numbers as to capture and handle subjective humans' appraisal that can be more adequately indicated by triangular fuzzy numbers. The combination of Fuzzy and VIKOR method enables decision-makers to incorporate unquantifiable, incomplete, non-obtainable and partial information into a decision model (Chang 2014). Interestingly the method had been widely used, for example, in ranking private universities in Taiwan (Wu et al. 2012), in evaluating performance of intercity bus service companies (Kuo \& Liang 2012), and evaluating service quality performance of medical and healthcare industry (Chang 2014). Fuzzy VIKOR had also been used to select the best automotive component in automotive industry (Girubha \& Vinodh 2012) and in ranking restaurants in hospitality industry (Tzeng et al. 2002).

Moreover, VIKOR can be used to develop a method for solving multiple-criteria decision making problems and applied it to solve a robot selection problem for material handling task (Devi 2011) as well as dealing with suppliers or vendors selection problems in the delivery process efficiency (Chen \& Wang 2009). In education industry, fuzzy VIKOR method was applied in school rankings, for example, in assessing the best school in district (Musani \& Jemain 2015) and evaluating school performance based on linguistic information (Musani \& Jemain 2013). However, 


\section{RESEARCH METHODOLOGY}

The main objective of the study is to rank school performance based on academic achievement in SPM examination for year 2016 and the data was collected from Jabatan Pendidikan Negeri Perlis, Malaysia. The data used is the percentage of candidates who obtained Sijil Pelajaran Malaysia (SPM) 2016 for five selected schools (School DSA, School SA, School A, School SS and School TB). All the data are based on school academic achievement for core subjects (Malay, English, History and Mathematics). This study ranked five selected schools (School DSA, School SA, School A, School SS and School TB) and to be evaluated by multiple conflict core subjects (Malay, English, History and Mathematics) using five grades for which are excellent (g5), honours (g4), average (g3), pass (g2) and fail (g1). The schools selected were from the same rural area, based on similarities in the courses offered and the selection did not involve religious schools, science and vocational or technical school where intakes were based on a number of preconditions (Musani \& Jemain, 2016).

The Fuzzy VIKOR method is used in this study for the calculation of school ranking and to decide the best core subject. The data were analyzed using Microsoft Excel 2007. The modified Fuzzy VIKOR and the fuzzy set theory methods are shown in following steps:

\section{Step 1: Identify appropriate linguistics variable and trapezoidal fuzzy number}

In this method, the ranking of school performance are assessed in linguistics variable can be expressed in positive trapezoidal fuzzy number. It is suggested by Zadeh (1975) which provides a level of knowledge that is more suitable to be used in fuzzy linguistic variables. As an example, the achievements of students on the course outcome for SPM result level are labeled as fail, pass, average, honours and excellent as the element of A positive trapezoidal fuzzy number can be defined as (a1, a2, a3, a4). The membership function $\mu_{\bar{A}}(x)$ is given by defined as:

$$
\mu_{\bar{A}}(x)= \begin{cases}0, & x<a_{1}, \\ \frac{x-a_{1}}{a_{2}-a_{1}}, & a_{1} \leq x \leq a_{2}, \\ 1, & a_{2} \leq x \leq a_{3}, \\ \frac{x-a_{4}}{a_{3}-a_{4},}, & a_{3} \leq x \leq a_{4}, \\ 0, & x>a_{4} .\end{cases}
$$

The algebraic operation for the trapezoidal fuzzy number can be addition, multiplication and subtraction. Given any two positive trapezoidal fuzzy numbers, $A=(a 1, a 2, a 3, a 4) \quad B=(b 1, b 2, b 3, b 4)$ and a positive real number r, some main operations of fuzzy numbers A and B were practiced by Liu et al. (2012).

$\mathrm{A}+\mathrm{B}=(\mathrm{a} 1+\mathrm{b} 1, \mathrm{a} 2+\mathrm{b} 2, \mathrm{a} 3+\mathrm{b} 3, \mathrm{a} 4+\mathrm{b} 4)$

$\mathrm{A}-\mathrm{B}=(\mathrm{a} 1-\mathrm{b} 1, \mathrm{a} 2-\mathrm{b} 2, \mathrm{a} 3-\mathrm{b} 3, \mathrm{a} 4-\mathrm{b} 4)$

$\mathrm{A} \times \mathrm{B} \approx(\mathrm{a} 1 \mathrm{~b} 1, \mathrm{a} 2 \mathrm{~b} 2, \mathrm{a} 3 \mathrm{~b} 3, \mathrm{a} 4 \mathrm{~b} 4)$

$\mathrm{r} \times \mathrm{B} \approx(\mathrm{rb} 1, \mathrm{rb} 2, \mathrm{rb} 3, \mathrm{rb} 4)$

Based on Eq. 1 and Eq. 2 (algebraic operation used was addition and multiplication in this study) with percentage score (aggregate) convert the linguistic variable in TzFN. This method used aggregation process because it's simplicity and flexibility of the operations and fits well with the goals of the study. As previously stated, the linguistic variables and a trapezoidal fuzzy number (TzFN) for this study was practiced by Zadeh (1975) listed in Table 1. 
Table 1: Linguistic variables for each level of achievement

\begin{tabular}{ccc}
\hline Linguistic & Variable & Trapezoidal fuzzy number (TzFN) \\
\hline Excellent & g5 & $(8,9,10,10)$ \\
Honours & g4 & $(6,7,8,9)$ \\
Average & g3 & $(3,4,5,7)$ \\
Pass & g2 & $(1,2,3,4)$ \\
Fail & g1 & $(0,0,0,2)$ \\
\hline
\end{tabular}

Step 2: Construct a fuzzy decision matrix.

$\tilde{X}=\sum_{i=1}^{m} \sum_{j=1}^{n} \sum x_{i j g} \times T z F N=\left[\widetilde{X}_{i j}\right]_{m \times n}=\left[\begin{array}{cccc}\tilde{x}_{11} & \tilde{x}_{12} & \cdots & \tilde{x}_{1 n} \\ \tilde{x}_{21} & \tilde{x}_{22} & \cdots & \tilde{x}_{2 n} \\ \vdots & \vdots & & \vdots \\ \tilde{x}_{m 1} & \tilde{x}_{m 2} & \cdots & \tilde{x}_{m n}\end{array}\right]$

$\mathrm{Xij}$ and $\mathrm{Wj}$ are linguistic variables denoted by trapezoidal fuzzy number where $\mathrm{Xij}$ is the rating of alternative Ai with respect to $\mathrm{Cj}$. Wj is the importance weight of the $\mathrm{j}$ th criterion. A trapezoidal fuzzy number can be defined as $\tilde{x}_{i j}=\left(\widetilde{a}_{i j}, \widetilde{b}_{i j}, \widetilde{c}_{i j}, \widetilde{d}_{i j}\right)$.

Step 3: Defuzzification of fuzzy decision matrix and fuzzy importance weight are determined.

$$
\begin{aligned}
& \operatorname{Defuzz}\left(\mathrm{x}_{\mathrm{ij}}\right)=\frac{\int \mu(\mathrm{x}) \cdot \mathrm{xdx}}{\int \mu(\mathrm{x}) \mathrm{dx}} \\
& \int_{\widetilde{x}_{i j 1}}^{\widetilde{x}_{i j 2}}\left(\frac{\widetilde{x}-\widetilde{x}_{i j}-\widetilde{x}_{i j 1}}{\widetilde{x}_{i j}}\right) \widetilde{x} d \widetilde{x}+\int_{\widetilde{x}_{i j 2}}^{\widetilde{x}_{i j}} \widetilde{x} d x+\int_{\widetilde{x}_{i j 3}}^{\widetilde{x}_{i j}}\left(\frac{\widetilde{x}_{i j 4}-\widetilde{x}}{\widetilde{x}_{i j 4}-\widetilde{x}_{i j 3}}\right) \cdot \widetilde{x} d \widetilde{x} \\
& =\int_{\widetilde{x}_{i j 1}}^{\widetilde{x}_{i 2}}\left(\frac{\widetilde{x}-\widetilde{x}_{i j 1}}{\widetilde{x}_{i j 2}-\widetilde{x}_{i j 1}}\right) d \widetilde{x}+\int_{\widetilde{x}_{i j 2}}^{\widetilde{x}_{i j 3}} \mathrm{dx}+\int_{\widetilde{x}_{i j 3}}^{\widetilde{x}_{i j}}\left(\frac{\widetilde{x}-\widetilde{x}_{i j 1}}{\widetilde{x}_{i j 2}-\widetilde{x}_{i j 1}}\right) d \widetilde{x} \\
& \frac{-\widetilde{\mathrm{x}}_{\mathrm{ij} 1} \widetilde{\mathrm{x}}_{\mathrm{ij} 2}+\widetilde{\mathrm{x}}_{\mathrm{ij} 3} \widetilde{\mathrm{x}}_{\mathrm{ij} 4}+\frac{1}{3}\left(\widetilde{\mathrm{x}}_{\mathrm{ij} 4}-\widetilde{\mathrm{x}}_{\mathrm{ij} 3}\right)^{2}-\frac{1}{3}\left(\widetilde{\mathrm{x}}_{\mathrm{ij} 2}-\widetilde{\mathrm{x}}_{\mathrm{ij} 1}\right)^{2}}{-\widetilde{\mathrm{x}}_{\mathrm{ij} 1}-\widetilde{\mathrm{x}}_{\mathrm{ij} 2}+\widetilde{\mathrm{x}}_{\mathrm{ij} 3}+\widetilde{\mathrm{x}}_{\mathrm{ij} 4}}
\end{aligned}
$$

Where the following is fuzzy important weight can be calculated as:

$$
\begin{gathered}
\widetilde{\widetilde{x}}_{n}=\frac{1}{M} \sum_{m=1}^{M} \widetilde{x}_{m n}, 0 \leq \widetilde{w}_{j} \leq 1, \\
\widetilde{w}_{j}=\frac{\widetilde{s}_{j}}{\sum_{j=1}^{n} \widetilde{s}_{j}} \\
\widetilde{W}=\left[\widetilde{w}_{1}, \widetilde{w}_{2}, \ldots, \widetilde{w}_{n}\right]
\end{gathered}
$$


$\mathrm{M}$ is the Total number of alternative, ${ }^{\tilde{S}_{j}}$ is standard deviation value for criteria ${ }_{n}, \widetilde{w}_{j}$ is the important weight of the criterion ${ }^{c}{ }_{j}$, While, $\overline{\widetilde{x}}_{n}$ is mean of rating of the alternative $A_{i}$ with respect to ${ }^{c_{j}}$ and $\widetilde{x}_{m n}=$ total rating of the alternative ${ }^{A_{i}}$ with respect to ${ }^{c_{j}}$.

Step 4: Determine the best value ${ }^{\left(x_{j}^{*}\right)}$ and worst value ${ }^{\left(x_{j}^{-}\right)}$for all criteria using the equation bellow: $\mathrm{x}_{\mathrm{j}}^{*}=\max _{\mathrm{i}} \mathrm{x}_{\mathrm{ij}}, \quad \mathrm{x}_{\mathrm{j}}^{-}=\min _{\mathrm{i}} \mathrm{x}_{\mathrm{ij}}$.

Step 5: Compute the values of utility index, $\mathrm{Si}$, and value of regret index, Ri, using the following equation practice from Opricovic and Tzeng (2003).

$$
\begin{aligned}
& S_{i}=\sum_{j=1}^{n} \frac{w_{j}\left(x_{j}^{*}-x_{i j}\right)}{\left(x_{j}^{*}-x_{j}^{-}\right)} \\
& R_{i}=\max _{j}\left[w_{j}\left(\frac{x_{j}^{*}-x_{i j}}{x_{j}^{*}-x_{j}^{-}}\right)\right]
\end{aligned}
$$

Step 6: The index VIKOR, Qi is calculated by:

$$
Q_{i}=\left(\frac{v\left(S_{i}-S^{-}\right)}{S^{+}-S^{-}{ }_{j}}\right)+\frac{(1-v)\left(R_{i}-R^{-}\right)}{R^{+}-R^{-}}
$$

Where,

$$
\tilde{\mathrm{S}}^{+}=\max _{\mathrm{i}} \tilde{\mathrm{S}}_{\mathrm{i}}, \tilde{\mathrm{S}}^{-}=\min _{\mathrm{i}} \tilde{\mathrm{S}}_{\mathrm{i}} \quad \mathrm{R}^{+}=\max _{\mathrm{i}} \mathrm{R}_{\mathrm{i}}, \mathrm{R}^{-}=\min _{\mathrm{i}} \mathrm{R}_{i}
$$

Given the $\mathrm{v}$ is introduced as the weight of the strategy of the maximum group utility and usually $\mathrm{v}=0.5$.

Step 7: Rank the alternative by sorting each Si, Ri and Qi in ascending order.

Step 8: Proposing compromise solution using two conditions.

Compromise solution is considered only if two conditions $\mathrm{C} 1$ and $\mathrm{C} 2$ are satisfied.

C1: Acceptable advantage:

$$
\mathrm{Q}_{\mathrm{A}_{2}}-\mathrm{Q}_{\mathrm{A}_{1}} \geq \frac{1}{(\mathrm{M}-1)}
$$

Where, $A_{2}$ is the second position in the alternatives ranked by Q, $A_{1}$ is the first position in the alternatives ranked by $\mathrm{Q}$, and $\mathrm{M}$ is total number of alternative. 
C2: Acceptable stability in decision making:

Alternative, $A_{1}$ must also be the best ranked by S or/ and R. When one of the condition is not satisfied, a set of compromise solutions will be suggested below:

1) Alternative $\mathrm{A} 1$ and $\mathrm{A} 2$ if only $\mathrm{C} 2$ is not satisfied or

2) Alternative $\mathrm{A} 1, \mathrm{~A} 2, \ldots . . \mathrm{Am}$ if condition $\mathrm{C} 1$ is not satisfied. Am is calculated using the equation

$$
\mathrm{Q}_{\mathrm{A}_{\mathrm{m}}}-\mathrm{Q}_{\mathrm{A}_{1}}<\frac{1}{\mathrm{M}-1}
$$

\section{RESULTS AND DISCUSSIONS}

Based on the result of the fuzzy VIKOR analyses shown in Figure 1, the ascending rank suggested that DSA (SMK Dato' Sheikh Ahmad) has the best criteria among the other five candidate schools. DSA has been selected as the best school by satisfying both condition $(\mathrm{C} 1)$ and $(\mathrm{C} 2)$ with validation using least VIKOR index value v $=0.5$. DSA has the lowest VIKOR index, $Q_{i}$ value which is 0.000 . A (SMK Arau) was second in rank with 0.803 score, followed by SA (SMK Syed Ahmad) with 0.872 score, SS (SMK Syed Sirajuddin) is the second last with 0.892 score and TB (SMK Tengku Budriah) is last rank with the highest VIKOR index value which is 1.001 .

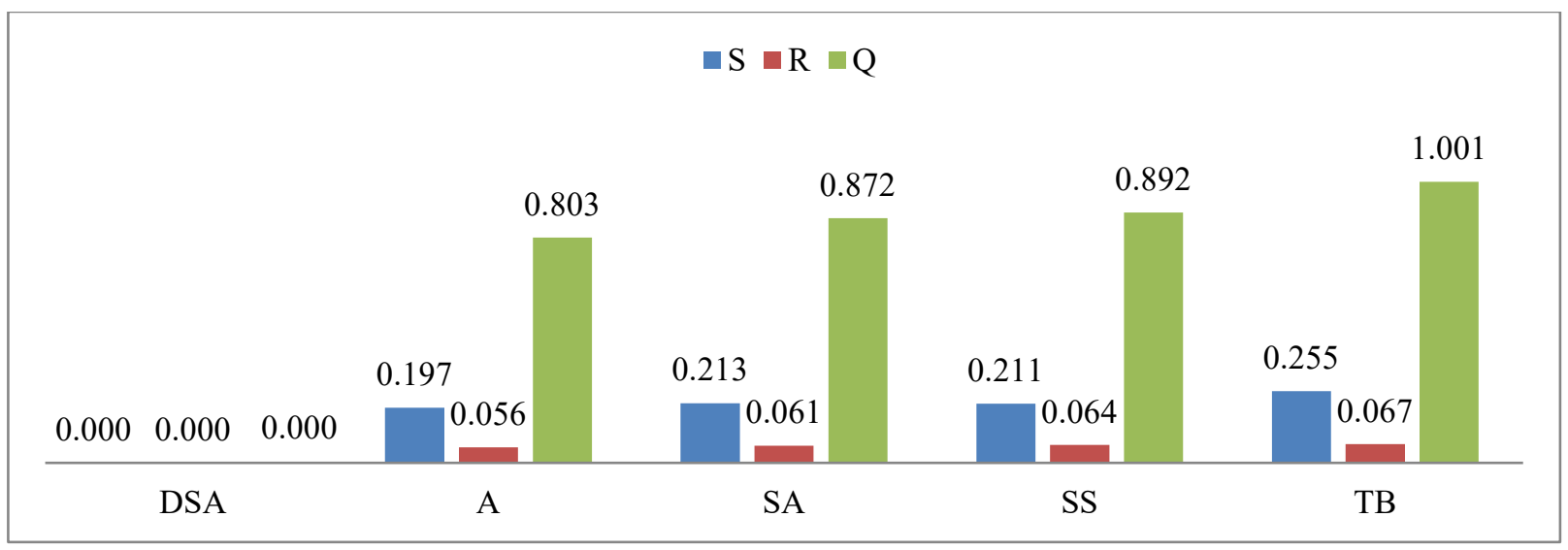

Figure 1: Graph ranking of $S, R$ and $Q$

\section{CONCLUSION}

The case study proved the ability of the proposed fuzzy MCDM model to effectively solve school ranking problem under fuzzy environment. Using this method, the ranking of schools assessed in linguistics variable by trapezoidal fuzzy numbers and the importance weight of the criteria are evaluated in crisp value. The study used fuzzy VIKOR method to determine the priority rank for the performance of five secondary schools in Arau, Perlis. The result shows that SMK Dato' Sheikh Ahmad is the best school because it has the lowest VIKOR index value which is 0.000 . SMK Arau is second in ranking with 0.803 score, followed by SMK Syed Ahmad with 0.872 score, SMK Syed Sirajuddin as the second last with 0.892 score and lastly SMK Tengku Budriah with the highest VIKOR index value which is 1.001 . By using the proposed approach, the ambiguity involved in the data evaluated can be effectively represented and processed to assure a more effective evaluation process. In addition, the results of this study serve as a reference point 
for schools and educational institutions in their efforts to improve performance and conduct assessments to form the basis of academic and education.

\section{RECOMMENDATIONS}

Future research is recommended to take place outside of Arau area which may utilized data obtain from boarding schools, religious schools and vocational or technical schools to reflect a more accurate performance of schools in Perlis. The researchers suggested that future research may add a fuzzy theory (e.g., Fuzzy AHP) or use other analytical methods before applying Fuzzy VIKOR to rank the school performance. Other linguistics variable like triangular fuzzy numbers and other defuzzification tehniques for this study can also be added.

\section{REFERENCES}

Chang, T. H. (2014). Fuzzy VIKOR method: a case study of the hospital service evaluation in Taiwan. Information Sciences, 271, 196-212.

Chen, L. Y., \& Wang, T. C. (2009). Optimizing partners' choice in IS/IT outsourcing projects: The strategic decision of fuzzy VIKOR. International Journal of Production Economics, 120(1), 233-242.

Devi, K. (2011). Extension of VIKOR method in intuitionistic fuzzy environment for robot selection. Expert Systems with Applications, 38(11), 14163-14168.

Girubha, R. J., \& Vinodh, S. (2012). Application of fuzzy VIKOR and environmental impact analysis for material selection of an automotive component. Materials and Design, 37, 478-486.

Kuo, M. S., \& Liang, G. S. (2012). A soft computing method of performance evaluation with MCDM based on interval-valued fuzzy numbers. Applied Soft Computing, 12(1), 476-485.

Liu, H. C., Liu, L., Liu, N., \& Mao, L. X. (2012). Risk evaluation in failure mode and effects analysis with extended VIKOR method under fuzzy environment. Expert Systems with Applications, 39(17), 12926-12934.

Musani, S., \& Jemain, A. A. (2013). A fuzzy MCDM approach for evaluating school performance based on linguistic information. AIP Conference Proceedings, 1571(1), 1006-1012.

Musani, S., \& Jemain, A. A. (2015). Ranking schools' academic performance using a fuzzy VIKOR. Journal of Physics: Conference Series, 622(1), 12-36.

Musani, S., \& Jemain, A. A. (2016). Ubah suaian gred pencapaian pelajar dalam pemeringkatan sekolah menggunakan pendekatan VIKOR. Journal of Quality Measurement and Analysis, 12(1-2), 67-78.

Opricovic, S., \& Tzeng, G. H. (2003). Defuzzification within a multicriteria decision model. International Journal of Uncertainty, Fuzziness and Knowledge-Based Systems, 11(05), 635-652.

Opricovic, S., \& Tzeng, G. H. (2007). Extended VIKOR method in comparison with outranking methods. European Journal of Operational Research, 178(2), 514-529. 
Rezaie, K., Ramiyani, S. S., Nazari-Shirkouhi, S., \& Badizadeh, A. (2014). Evaluating performance of Iranian cement firms using an integrated fuzzy AHP-VIKOR method. Applied Mathematical Modelling, 38(21), 5033-5046.

Tierney, J. (2013). Why High-School Rankings Are Meaningless—and Harmful. The Atlantic, May 28. Retrieved from https://www.theatlantic.com/national/archive/2013/05/why-high-school-rankingsare-meaningless-and-harmful/276122/

Tzeng, G. H., Teng, M. H., Chen, J. J., \& Opricovic, S. (2002). Multicriteria selection for a restaurant location in Taipei. International Journal of Hospitality Management, 21(2), 171-187.

Wu, H. Y., Chen, J. K., Chen, I. S., \& Zhuo, H. H. (2012). Ranking universities based on performance evaluation by a hybrid MCDM model. Measurement, 45(5), 856-880.

Zadeh, L. A. (1975). The concept of a linguistic variable and its application to approximate reasoning-I. Information Sciences, 8(3), 199-249. 